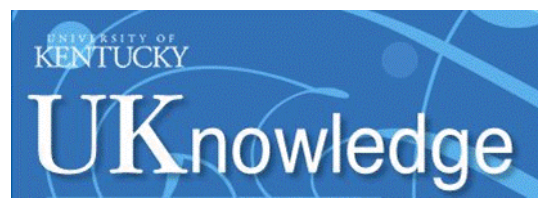

University of Kentucky

UKnowledge

\title{
Racial/Ethnic Disparities in Survival among Men Diagnosed with Prostate Cancer in Texas
}

Arica L. White

University of Texas Health Science Center at Houston, awhite5@cdc.gov

Ann L. Coker

University of Kentucky, ann.coker@uky.edu

Xianglin L. Du

University of Texas Health Science Center at Houston, xianglin.I.du@uth.tmc.edu

Katherine S. Eggleston

University of Texas Health Science Center at Houston, katherine.s.eggleston@uth.tmc.edu

Melanie Williams

Texas Department of State Health Services, melanie.williams@dshs.state.tx.us

Follow this and additional works at: https://uknowledge.uky.edu/crvaw_facpub

Part of the Oncology Commons, Public Health Commons, and the Urology Commons

Right click to open a feedback form in a new tab to let us know how this document benefits you.

\section{Repository Citation}

White, Arica L.; Coker, Ann L.; Du, Xianglin L.; Eggleston, Katherine S.; and Williams, Melanie, "Racial/Ethnic Disparities in Survival among Men Diagnosed with Prostate Cancer in Texas" (2011). CRVAW Faculty Journal Articles. 253.

https://uknowledge.uky.edu/crvaw_facpub/253

This Article is brought to you for free and open access by the Center for Research on Violence Against Women at UKnowledge. It has been accepted for inclusion in CRVAW Faculty Journal Articles by an authorized administrator of UKnowledge. For more information, please contact UKnowledge@lsv.uky.edu. 


\section{Racial/Ethnic Disparities in Survival among Men Diagnosed with Prostate Cancer in Texas}

Digital Object Identifier (DOI)

https://doi.org/10.1002/cncr.25671

Notes/Citation Information

Published in Cancer, v. 117, no. 5, p. 1080-1088.

Copyright @ 2010 American Cancer Society

The copyright holder has granted the permission for posting the article here.

This is the accepted version of the following article: White, A., Coker, A. L., Du, X. L., Eggleston, K. S., \& Williams, M. (2011). Racial/ethnic disparities in survival among men diagnosed with prostate cancer in Texas. Cancer, 117(5), 1080-1088, which has been published in final form at https://doi.org/10.1002/ cncr.25671. This article may be used for non-commercial purposes in accordance with Wiley Terms and Conditions for Self-Archiving. 


\title{
Racial/ethnic disparities in survival among men diagnosed with prostate cancer in Texas
}

\author{
Arica L. White, PhD, MPH ${ }^{1}$, Ann L. Coker, $\mathrm{PhD}^{2}$, Xianglin L. Du, MD, PhD¹, Katherine S. \\ Eggleston, $\mathbf{M S P H}^{1}$, and Melanie Williams, $\mathrm{PhD}^{3}$ \\ ${ }^{1}$ School of Public Health, Division of Epidemiology, University of Texas Health Science Center, \\ Houston, TX 77030, USA \\ ${ }^{2}$ College of Medicine, University of Kentucky, Department of Obstetrics and Gynecology, \\ Lexington, KY, 40506, USA \\ ${ }^{3}$ Texas Department of State Health Services, Cancer Epidemiology and Surveillance Branch, \\ Austin, TX, 78756, USA
}

\begin{abstract}
BACKGROUND-To the authors' knowledge, few studies to date have examined racial differences in prostate cancer survival while controlling for socioeconomic status (SES). No such studies have examined this association in Texas, a large state with significant ethnic and racial diversity. The objective of this analysis was to determine whether racial disparities in survival for men diagnosed with prostate cancer in Texas from 1995 through 2002 remained after adjusting for SES, rural residence, and stage of disease.
\end{abstract}

METHODS-A cohort of 87,449 men who were diagnosed with prostate cancer was identified from the Texas Cancer Registry. The SES measure was based on census tract data reflecting median household income, median home value, and percentages of men living below poverty, with a college education, and with a management or professional occupation. The 5-year survival rates were calculated using the Kaplan-Meier method and Cox proportional hazard modeling was used to estimate hazard ratios (HRs) for race and all-cause and disease-specific mortality.

RESULTS-After adjusting for SES, age, stage of disease, tumor grade, year of diagnosis, and rural residence, both black and Hispanic men were more likely (adjusted HR [aHR], 1.70 [95\% confidence interval (95\% CI), 1.58-1.83] and aHR, 1.11 [95\% CI, 1.02-1.20], respectively) to die of prostate cancer compared with white men. The pattern of survival disadvantage for black men held for those diagnosed with localized disease and advanced disease, and for those with an unknown stage of disease at diagnosis.

CONCLUSIONS-Substantial racial disparities in prostate cancer survival were found for men in Texas. Future studies should incorporate treatment data as well as comorbid conditions because this information may explain noted survival disparities.

\section{INTRODUCTION}

Prostate cancer is the most frequently diagnosed cancer in men in the United States. 1 It is estimated that 192,280 new cases and 27,360 deaths will have occurred from prostate cancer in $2009 .{ }^{1}$ Despite the medical advances in detection and treatment, the burden of mortality

Correspondence to: Arica White, PhD, MPH, Centers for Disease Control and Prevention, Division of Cancer Prevention and Control, Epidemiology and Applied Research Branch, 4770 Buford Hwy NE, Mailstop K-55, Atlanta, GA 30341-3717, Tel:770.488.3001, awhite5@cdc.gov. 
varies by race/ethnicity. For the years 2000 to 2004, the age-adjusted mortality was much higher for non-Hispanic black men than for non-Hispanic white men (59.4 per 100,000 vs. 24.6 per 10,000). ${ }^{1}$ Hispanics, American Indian/Alaskan Natives, and Asian American and Pacific Islanders all had mortality rates lower than these 2 groups (20.6 per 100,000, 21.1 per 100,000 , and 11.0 per 100,000 , respectively). ${ }^{1}$

Racial/ethnic disparities in prostate cancer survival have also been documented in the literature, ${ }^{2-12}$ and can be attributed to differences in socioeconomic status (SES),, $13-16$ tumor stage at diagnosis, ${ }^{17,18}$ physician characteristics, ${ }^{19}$ rural residence, ${ }^{20}$ and treatment. ${ }^{18-25}$ For studies that examined prostate cancer survival disparities by race/ethnicity and incorporated SES, $, 3,5,7,8,28$ conflicting results regarding the role of SES in explaining survival disparities were found. These inconsistencies are likely due to the utilization of different proxy measures of SES, as well as not accounting for differences in stage of disease at diagnosis, tumor characteristics, treatment, and other prognostic factors.

The majority of studies ${ }^{3,5,6,8-11,26-30}$ have explored the relation between race/ethnicity and survival by comparing non-Hispanic black and non-Hispanic white men. To the best of our knowledge, few studies to date have examined disparities among other racial/ethnic groups. 2,4,5,7,12 Only 1 study examined outcomes for Hispanic men and incorporated SES in association with race/ethnicity to determine their role in prostate cancer survival, in addition to factors such as cancer stage, tumor grade, comorbidities, and treatment. ${ }^{2}$ Furthermore, 2 studies examined the role of both race/ethnicity and SES in survival and included Asian Americans in their analysis. ${ }^{5,7}$ One of these studies ${ }^{7}$ incorporated prognostic factors such as treatment, tumor grade, and stage of disease at diagnosis. To the best of our knowledge, no study has been reported for men with prostate cancer residing in Texas.

Therefore, this study aimed to assess disparities in survival among an ethnically diverse group of men with prostate cancer who resided in Texas. The large population and racial/ ethnic diversity provides an optimal setting in which to study what factors (including SES) explain racial disparities in prostate cancer survival and also to study several ethnic groups of all ages that were under-represented in the literature. Although a previous study, ${ }^{2}$ which used the Surveillance, Epidemiology, and End Results Program (SEER)-Medicare linked database and incorporated racial/ethnicity, SES, and prognostic factors, found that differences between racial/ethnic groups are because of SES, it is unclear whether these differences are similar in men aged $<65$ years and at the state level in Texas, which is not part of the SEER program. We hypothesized that compared with non-Hispanic white men, non-Hispanic black men and Hispanic men would have poorer survival and Asian American/Pacific Islander men would have better survival after controlling for differences in patient demographics, neighborhood SES, tumor characteristics, rural residence, and year of diagnosis.

\section{MATERIALS AND METHODS}

\section{Data Sources}

Incident prostate cancer cases were obtained from the Texas Cancer Registry, which is a population-based database that collects data regarding cancers diagnosed in the state of Texas. It has been annually awarded gold certification by the North American Association of Central Cancer Registries since the submission of its 2003 cancer incidence data. Gold certification indicates that the program has a case completeness rate $>95 \%$. The incident prostate cancer cases, which were comprised of men aged $\geq 25$ years who were diagnosed with invasive primary prostate cancer (International Classification of Diseases for Oncology, 3rd edition [ICD-0-3] code C61.93) between January 1, 1995 and December 31, 2002, were linked with the Texas Department of State Health Services mortality data through December 
31, 2003 to obtain vital status. Death certificate information including date of death and underlying cause of death was also acquired. The last date of follow-up was December 31, 2003. Institutional Review Boards from the Texas Department of State Health Services and the University of Texas Health Science Center at Houston approved this study protocol.

\section{Study Population}

Race/ethnicity, which was defined by the race and Spanish/Hispanic origin variables abstracted from medical records, was categorized as non-Hispanic white (referent group), non-Hispanic black, Hispanic, and Asian/Pacific Islander.

The study population was comprised of 87,444 men diagnosed between January 1, 1995 and December 31, 2002 with prostate cancer. All men were Texas residents aged $\geq 25$ years. Of these men, $74.9 \%(65,478)$ were non-Hispanic white (hereinafter referred to as white), $12.3 \%(10,770)$ were non-Hispanic black (hereinafter referred to as black), $12.2 \%(10,650)$ were Hispanic, and $0.62 \%$ (546) were Asian/Pacific Islander (hereinafter referred to as Asian).

\section{Prostate Cancer Survival Definition}

Survival time in days was calculated from the date of diagnosis to the date of death. For cases that were missing the day of diagnosis, it was defined as the 15 th of the month $(n=8753)$. For cases that only included the year of diagnosis but not the month or day, the date of diagnosis was defined as June 15th $(\mathrm{n}=1571)$. Prostate cancer-specific mortality was defined as death with prostate cancer as the underlying cause. Patients who died of causes other than prostate cancer or were still alive at the time of last follow-up (December 31, 2003) were censored. All-cause mortality was defined as death from any underlying cause of death. Underlying cause of death was defined by the Texas Department of State Health Services Vital Statistics guidelines.

\section{Socioeconomic Status}

A census-derived composite variable was created to measure SES at the block group level. All data were geocoded using Atlas (version 4.0; Lebanon, $\mathrm{NH}$ ). The batch method was initially used and any addresses that did not match were manually geocoded by relaxing attributes such as ZIP code and street directionals. Although the majority of cases matched, $20 \%$ of cases did not and were randomly assigned to the block group of a randomly matched case that was identical with regard to their ZIP code, race, age, and sex. The data were then linked with census block group data to create an SES composite index. ${ }^{31}$ Measures included in this index were the median household income, percentage of men living below poverty, percentage with a college education, percentage with a management/professional occupation, and median home value. These socioeconomic variables were first recoded to ensure that lower values represented higher SES (median household income was made negative). The values were then converted into normal scores. The 5 measures of SES were then equally weighted, summed, and categorized using the quintile distribution for all men with prostate cancer. Further information on creating this SES composite index is detailed elsewhere. $^{32}$

\section{Patient and Tumor Characteristics}

The following patient and tumor characteristics were also assessed in the study: year of diagnosis (1995-2002), age (continuous), SEER summary tumor stage (localized, regional/ distant, or unknown), tumor grade (well differentiated, moderately differentiated, poorly differentiated, undifferentiated, or unknown), and rural residence (urban, large town, small town, or rural). Rural residence was defined using the Rural Urban Commuting Area Codes 
(RUCA), which uses Census Bureau urbanized area and urban cluster definitions in combination with work commuting information to characterize census tracts regarding their rural and urban status. ${ }^{33}$ The data were aggregated into the 4 categories mentioned above using Categorization A. ${ }^{34}$

\section{Statistical Analysis}

All data were analyzed using the statistical software package Intercooled Stata (version 9.0; StataCorp, College Station, TX). The distribution of baseline characteristics among the racial/ethnic groups was assessed for differences using the chi-square statistic. The 5-year survival was estimated using the Kaplan-Meier method. The log-rank test for equality of survivor functions was used to determine whether there were differences in the observed survival by race/ethnicity and SES. Cox proportional hazards regression models were used to estimate the relative risk of dying of prostate cancer after adjusting for age, SES, tumor stage, tumor grade, rural residence, and year of diagnosis. These models were also stratified by tumor stage.

\section{RESULTS}

Table 1 presents the distribution of patient demographic and tumor characteristics for Asian, Hispanic, black, and white men who were diagnosed with prostate cancer between 1995 and 2002. There were significant differences when comparing these groups. Black men were diagnosed with prostate cancer an average age of 1 year earlier than white men. Black, Asian, and Hispanic men were more likely to be diagnosed at a regional or distant stage compared with white men, and black men were more likely to be have an unknown stage of disease at diagnosis. Compared with white men, black and Asian men were less likely and Hispanic men were more likely to have well-differentiated tumors. Furthermore, there were statistically significant differences with regard to SES and rural residence when comparing white men with Asian, black, and Hispanic men. Significantly higher percentages of black (32.4\%) and Hispanic men $(34.1 \%)$ resided in very low socioeconomic areas compared with $7.9 \%$ of white men, whereas a greater percentage of Asian men (43.8\%) resided in very high socioeconomic areas compared with white men (35.5\%). Although the majority of all men resided in urban areas, Hispanic and black men were less likely than white men to live in rural areas of small towns.

Table 2 presents the unadjusted all-cause and prostate cancer-specific probability of surviving $\geq 5$ years by race/ethnicity and SES. Overall, survival was greatest for Asian men and lowest for black men. The probability of surviving 5 years independent of the cause of death was $79 \%$ for white men, $70 \%$ for black men, $74 \%$ for Hispanic men, and $86 \%$ for Asian men. Prostate-specific survival probabilities followed a similar pattern by race: $92 \%$ for white men, $83 \%$ for black men, $88 \%$ for Hispanic men, and $94 \%$ for Asian men. Those who resided in neighborhoods of very low SES had poorer survival (70\% all-cause survival) compared with those who lived in areas with very high SES (83\%). Similarly, prostate cancer 5-year survival probabilities ranged from $85 \%$ for those residing in very low SES areas to $94 \%$ for those residing in very high SES areas.

Table 3 compares the mortality associated with race/ethnicity in men diagnosed with prostate cancer by stage at diagnosis during the years 1995 through 2002. After adjusting for SES, age, tumor stage, tumor grade, rural residence, and year of diagnosis, black men were more likely to die (adjusted hazard ratio [aHR], 1.36; 95\% confidence interval [95\% CI], 1.30-1.42) and Asian men were less likely to die (aHR, 0.65; 95\% CI, 0.52-0.82) compared with white men. For black men, the same trend was evident when their cancer was diagnosed at either a local, regional/distant, or unknown stage (aHR, 1.28 [95\% CI, 1.191.36]; aHR, 1.49 [95\% CI, 1.37-1.63]; and aHR, 1.35 [95\% CI, 1.25-1.46], respectively.) 
Asian men were less likely than white men to die when their cancer was diagnosed at a local stage (aHR, 0.49; 95\% CI, 0.33-0.73).

With regard to overall prostate-specific mortality, compared with white men, black (aHR, 1.70; 95\% CI, 1.58-1.83) and Hispanic men (aHR, 1.11; 95\% CI, 1.02-1.20) were more likely to die of prostate cancer (Table 4). Of those diagnosed at a local stage of disease, black and Hispanic men were more likely to die compared with white men (aHR, 1.52 [95\% CI, 1.30-1.78] and aHR, 1.23 [95\% CI, 1.05-1.44], respectively). Black men were also more likely than white men to die when diagnosed at regional/distant and unknown stages (aHR, 1.70 [95\% CI, 1.52-1.89] vs. aHR, 1.80 [95\% CI, 1.57-2.05], respectively).

Table 5 shows predictors of prostate-specific mortality. Black men had a significantly higher risk of dying (HR, 2.01; 95\% CI, 1.89-2.17) compared with white men in the unadjusted model. However, this risk was reduced after full adjustment for age, year of diagnosis, tumor stage, tumor grade, SES, and urban/rural residence (HR, 1.70; 95\% CI, 1.58-1.83). For Hispanic men, the risk of death was higher than that for white men (HR, 1.55; 95\% CI, 1.43-1.67) in the crude model. However, after full adjustment, their risk decreased but remained higher than that of white men (HR, 1.11; 95\% CI, 1.02-1.20).

Finally, to ensure similar follow-up time after diagnosis, we restricted the analysis to men diagnosed between 1995 and 1998 and followed through 2003. The results for overall and stage-specific all-cause mortality and prostate cancer-specific mortality were very similar to the rates for men diagnosed from 1995 through 2002 (Table 3), and therefore are not presented.

\section{DISCUSSION}

Although many studies have documented racial/ethnic disparities in prostate cancer survival, 2-12 to the best of our knowledge few have included Hispanic and Asian men in their analyses and no study of this relation has been performed for men residing in Texas. Our finding that black and Hispanic men in Texas have higher mortality whereas Asian men have lower mortality from prostate cancer compared with white men is consistent with studies that have explored race/ethnicity and mortality for these groups. ${ }^{2-11}$

Racial/ethnic disparities in survival have been attributed to many factors, including differences in SES. ${ }^{2,7,8,26}$ A large proportion of black and Hispanic men resided in low SES neighborhoods, and therefore controlling for SES was important for examining the relation between ethnicity and survival. However, there may be residual confounding of SES because we were not able to control for differences in SES at the individual level. The results of the current study are consistent with studies that incorporated SES while examining survival differences between race/ethnicity and found that the racial/ethnic differences persisted after controlling for SES. $.3,5,8$

The finding that black and Hispanic men have higher mortality from prostate cancer may be explained by patient, provider, and health care system factors that influence treatment. A mortality disadvantage was present at each stage of diagnosis for black men, even after controlling for SES, tumor grade, and other factors. This disadvantage may be because of differences in the receipt of treatment and access to high-quality healthcare. There is a significant survival benefit in men who receive radical prostatectomy compared with those treated with watchful waiting or radiotherapy. ${ }^{36}$ However, studies have documented that black men are less likely than white men to receive definitive treatment ${ }^{8,37}$ and radical prostatectomy, ${ }^{37-43}$ and are more likely to be treated with watchful waiting ${ }^{40}$ or not receive treatment at all. ${ }^{38,39,44}$ Furthermore, Tewari et al found that lower prostate cancer survival rates for African American men were explained by differences in SES and lower surgical 
treatment rates. ${ }^{45}$ In addition to differences in receipt of treatment, previous research has shown that minority men are less likely to have access to high-quality healthcare. Bach et al found that physicians treating black patients may be less well trained clinically and may have limited access to clinical resources such as high-quality diagnostic imaging and highquality subspecialists than physicians treating white patients. ${ }^{19}$

Differences in tumor behavior may explain the disparities in prostate cancer mortality observed in the current study. Previous research has shown that black men are at a greater risk of developing prostate cancer and are more likely to have more aggressive tumors, ${ }^{17,18}$ which may explain an advanced stage of disease at the time of presentation and possibly poorer subsequent survival. In this study, when compared with white men, black men were slightly more likely to present with a regional/distant stage of disease and have poorly differentiated tumors. Furthermore, the pattern of survival disadvantage for black men held for those diagnosed with both localized disease and advanced disease, and those with an unknown stage of disease at diagnosis. The risk of overall prostate cancer-specific mortality was reduced significantly after adjusting for socio-demographic factors, tumor grade, and stage, but black men still had poorer survival compared with white men.

There are several study strengths that support the validity of these findings. First, we were able to examine survival in men aged $\geq 25$ years and by race/ethnicity in traditionally understudied groups: Hispanic and Asian men. These data and findings were unique because to the best of our knowledge, no study to date has been conducted for men residing in Texas. Furthermore, we used population-based data that met high national data quality standards, including a cancer case completeness rate of $>95 \%$. Finally, using 8 years of data with 1year of follow-up yielded a large sample size $(n=87,449)$.

There were also a few limitations to the current study. First, there was limited information regarding patient-level, provider-level, and system-level factors. Thus, we were unable to incorporate the role that patient or physician treatment preferences, physician specialty, and health insurance play in the disparities between these groups. Second, we had limited clinical information and therefore were unable to account for differences in Gleason scores, prostate-specific antigen (PSA) levels, treatment, and comorbid conditions, which are reported to be associated with survival. ${ }^{18-25}$ However, in lieu of both Gleason scores and PSA levels at diagnosis, we used tumor grade at the time of diagnosis as a measure of tumor aggressiveness. Third, the sample size for Asian men was small and there may have been limited power to test the hypothesis that they had better survival than white men.

Nevertheless, our finding that Asian men had better all-cause survival is consistent with some previously published studies. ${ }^{5,7}$ Fourth, we did not have information regarding individual-level SES. Rather, we used a composite variable for neighborhood SES and therefore residual confounding may not have been adequately controlled for in our analyses.

In conclusion, substantial racial disparities in survival were found for men with prostate cancer who resided in Texas. Black and Hispanic men were more likely to die of prostate cancer and Asian men were less likely to die of all causes, even when adjusting for SES and stage of disease and tumor grade at diagnosis compared with white men. This study highlights the racial/ethnic disparities in prostate cancer survival in men residing in Texas. Future research is needed to examine patient-level, provider-level, and system-level factors that may that play a role in explaining the survival disparity.

\section{Acknowledgments}

We acknowledge the efforts of the Texas Cancer Registry in the creation of this database. The interpretation and reporting of these data are the sole responsibilities of the authors. This study is supported by a grant from the 
National Cancer Institute (5R21CA114330). Arica White was the recipient of a pre-doctoral fellowship under a National Cancer Institute grant (R25-CA057712).

\section{References}

1. American Cancer Society. Cancer Facts and Figures 2008. American Cancer Society; 2008.

2. Du XL, Fang S, Coker AL, Sanderson M, Aragaki C, Cormier JN, et al. Racial disparity and socioeconomic status in association with survival in older men with local/regional stage prostate carcinoma: findings from a large community-based cohort. Cancer. 2006; 106:1276-85. [PubMed: 16475208]

3. Godley PA, Schenck AP, Amamoo MA, Schoenbach VJ, Peacock S, Manning M, et al. Racial differences in mortality among Medicare recipients after treatment for localized prostate cancer. $\mathrm{J}$ Natl Cancer Inst. 2003; 95(22):1702-10. [PubMed: 14625261]

4. Lin SS, Clarke CA, Prehn AW, Glaser SL, West DW, O'Malley CD. Survival differences among Asian subpopulations in the United States after prostate, colorectal, breast, and cervical carcinomas. Cancer. 2002; 94(4):1175-82. [PubMed: 11920489]

5. Oakley-Girvan I, Kolonel LN, Gallagher RP, Wu AH, Felberg A, Whittemore AS. Stage at diagnosis and survival in a multiethnic cohort of prostate cancer patients. Am J Public Health. 2003; 93(10):1753-9. [PubMed: 14534233]

6. Pienta KJ, Demers R, Hoff M, Kau TY, Montie JE, Severson RK. Effect of age and race on the survival of men with prostate cancer in the Metropolitan Detroit tricounty area, 1973 to 1987. Urology. 1995; 45(1):93-101. discussion 01-2. [PubMed: 7817485]

7. Robbins AS, Koppie TM, Gomez SL, Parikh-Patel A, Mills PK. Differences in prognostic factors and survival among white and Asian men with prostate cancer, California, 1995-2004. Cancer. 2007; 110(6):1255-63. [PubMed: 17701951]

8. Robbins AS, Whittemore AS, Thom DH. Differences in socioeconomic status and survival among white and black men with prostate cancer. Am J Epidemiol. 2000; 151(4):409-16. [PubMed: 10695600]

9. Robbins AS, Whittemore AS, Van Den Eeden SK. Race, prostate cancer survival, and membership in a large health maintenance organization. Journal of the National Cancer Institute. 1998; 90(13): 986-90. [PubMed: 9665146]

10. Thompson I, Tangen C, Tolcher A, Crawford E, Eisenberger M, Moinpour C. Association of African-American ethnic background with survival in men with metastatic prostate cancer. J Natl Cancer Inst. 2001; 93(3):219-25. [PubMed: 11158191]

11. Powell IJ, Schwartz K, Hussain M. Removal of the financial barrier to health care: does it impact on prostate cancer at presentation and survival? A comparative study between black and white men in a Veterans Affairs system. Urology. 1995; 46(6):825-30. [PubMed: 7502424]

12. Goggins WB, Wong GK. Poor survival for US Pacific Islander cancer patients: evidence from the Surveillance, Epidemiology, and End Results database: 1991 to 2004. J Clin Oncol. 2007; 25(36): 5738-41. [PubMed: 18089868]

13. Howard G, Anderson RT, Russell G, Howard VJ, Burke GL. Race, socioeconomic status, and cause-specific mortality. Ann Epidemiol. 2000; 10(4):214-23. [PubMed: 10854956]

14. Tarman GJ, Kane CJ, Moul JW, Thrasher JB, Foley JP, Wilhite D, et al. Impact of socioeconomic status and race on clinical parameters of patients undergoing radical prostatectomy in an equal access health care system. Urology. 2000; 56(6):1016-20. [PubMed: 11113750]

15. Neal RD, Allgar VL. Sociodemographic factors and delays in the diagnosis of six cancers: analysis of data from the "National Survey of NHS Patients: Cancer". Br J Cancer. 2005; 92(11):1971-5. [PubMed: 15900296]

16. Ward E, Jemal A, Cokkinides V, Singh GK, Cardinez C, Ghafoor A, et al. Cancer disparities by race/ethnicity and socioeconomic status. CA Cancer J Clin. 2004; 54(2):78-93. [PubMed: 15061598]

17. Freedland SJ, Isaacs WB. Explaining racial differences in prostate cancer in the United States: sociology or biology? Prostate. 2005; 62(3):243-52. [PubMed: 15389726] 
18. Hoffman RM, Gilliland FD, Eley JW, Harlan LC, Stephenson RA, Stanford JL, et al. Racial and ethnic differences in advanced-stage prostate cancer: the Prostate Cancer Outcomes Study. J Natl Cancer Inst. 2001; 93(5):388-95. [PubMed: 11238701]

19. Bach PB, Pham HH, Schrag D, Tate RC, Hargraves JL. Primary care physicians who treat blacks and whites. N Engl J Med. 2004; 351(6):575-84. [PubMed: 15295050]

20. Jemal A, Ward E, Wu X, Martin HJ, McLaughlin CC, Thun MJ. Geographic patterns of prostate cancer mortality and variations in access to medical care in the United States. Cancer Epidemiol Biomarkers Prev. 2005; 14(3):590-5. [PubMed: 15767335]

21. Peters N, Armstrong K. Racial differences in prostate cancer treatment outcomes: a systematic review. Cancer Nurs. 2005; 28(2):108-18. [PubMed: 15815180]

22. Polednak AP. Prostate cancer treatment in black and white men: the need to consider both stage at diagnosis and socioeconomic status. J Natl Med Assoc. 1998; 90(2):101-4. [PubMed: 9510624]

23. Shavers V. Race/ethnicity and watchful waiting for initial management of prostate cancer. Journal of General Internal Medicine. 2004; 19:146-55. [PubMed: 15009794]

24. Underwood W 3rd, Jackson J, Wei JT, Dunn R, Baker E, Demonner S, et al. Racial treatment trends in localized/regional prostate carcinoma: 1992-1999. Cancer. 2005; 103(3):538-45. [PubMed: 15612083]

25. Underwood W 3rd, Wei J, Rubin MA, Montie JE, Resh J, Sanda MG. Postprostatectomy cancerfree survival of African Americans is similar to non-African Americans after adjustment for baseline cancer severity. Urol Oncol. 2004; 22(1):20-4. [PubMed: 14969799]

26. Optenberg SA, Thompson IM, Friedrichs P, Wojcik B, Stein CR, Kramer B. Race, treatment, and long-term survival from prostate cancer in an equal-access medical care delivery system. Jama. 1995; 274(20):1599-605. [PubMed: 7474244]

27. Polednak AP. Black-white differences in survival from late-stage prostate cancer. Ethn Dis. 2003; 13(2):220-5. [PubMed: 12785419]

28. Robbins AS, Yin D, Parikh-Patel A. Differences in prognostic factors and survival among White men and Black men with prostate cancer, California, 1995-2004. Am J Epidemiol. 2007; 166(1): 71-8. [PubMed: 17426038]

29. Halabi S, Small EJ, Vogelzang NJ, Barrier RC, George SL, Gilligan TD. Impact of race on survival in men with metastatic hormone-refractory prostate cancer. Urology. 2004; 64:212-17. [PubMed: 15302462]

30. Roach M 3rd, Lu J, Pilepich MV, Asbell SO, Mohiuddin M, Grignon D. Race and survival of men treated for prostate cancer on radiation therapy oncology group phase III randomized trials. J Urol. 2003; 169(1):245-50. [PubMed: 12478146]

31. Krieger N, Chen JT, Waterman PD, Soobader M-J, Subramanian SV, RC. Geocoding and monitoring US socioeconomic inequalities in mortality and cancer incidence: does choice of areabased measure and geographic level matter?-The Public Health Disparities Geocoding Project. Am J Epidemiol. 2002; 156:471-82. [PubMed: 12196317]

32. Coker A, Eggleston K, Du XLLR. Ethnic disparities in cervical cancer survival among Medicare eligible women in a multi-ethnic population. International Journal of Gynecological Cancer. In Press.

33. Rural Health Research Center. Rural-urban commuting area codes. [accessed July 10, 2008]. Available from URL: http://depts.washington.edu/uwruca/index.html

34. Rural Health Research Center. RUCA data: Using RUCA data. [accessed August 10, 2008]. Available from URL: http://depts.washington.edu/uwruca/uses.html

35. Jones BA, Liu WL, Araujo AB, Kasl SV, Silvera SN, Soler-Vila H, et al. Explaining the race difference in prostate cancer stage at diagnosis. Cancer Epidemiol Biomarkers Prev. 2008; 17(10): 2825-34. [PubMed: 18829446]

36. Liu L, Coker AL, Du XL, Cormier JN, Ford CE, Fang S. Long-term survival after radical prostatectomy compared to other treatments in older men with local/regional prostate cancer. $\mathrm{J}$ Surg Oncol. 2008; 97(7):583-91. [PubMed: 18381603]

37. Richert-Boe KE, Weinmann S, Shapiro JA, Rybicki BA, Enger SM, Van Den Eeden SK, et al. Racial differences in treatment of early-stage prostate cancer. Urology. 2008; 71(6):1172-6. [PubMed: 18279922] 
38. Desch CE, Penberthy L, Newschaffer CJ, Hillner BE, Whittemore M, McClish D, et al. Factors that determine the treatment for local and regional prostate cancer. Med Care. 1996; 34(2):152-62. [PubMed: 8632689]

39. Fowler JE Jr, Bigler SA, Bowman G, Kilambi NK. Race and cause specific survival with prostate cancer: influence of clinical stage, Gleason score, age and treatment. J Urol. 2000; 163(1):137-42. [PubMed: 10604331]

40. Klabunde CN, Potosky AL, Harlan LC, Kramer BS. Trends and black/white differences in treatment for nonmetastatic prostate cancer. Med Care. 1998; 36(9):1337-48. [PubMed: 9749657]

41. Mettlin CJ, Murphy GP, Cunningham MP, Menck HR. The National Cancer Data Base report on race, age, and region variations in prostate cancer treatment. Cancer. 1997; 80(7):1261-6. [PubMed: 9317177]

42. Morris CR, Snipes KP, Schlag R, Wright WE. Sociodemographic factors associated with prostatectomy utilization and concordance with the physician data query for prostate cancer (United States). Cancer Causes Control. 1999; 10(6):503-11. [PubMed: 10616820]

43. Imperato PJ, Nenner RP, Will TO. Radical prostatectomy: lower rates among African-American men. J Natl Med Assoc. 1996; 88(9):589-94. [PubMed: 8855651]

44. Gilliland FD, Hunt WC, Key CR. Ethnic variation in prostate cancer survival in New Mexico. Cancer Epidemiol Biomarkers Prev. 1996; 5(4):247-51. [PubMed: 8722215]

45. Tewari A, Horninger W, Pelzer AE, Demers R, Crawford ED, Gamito EJ, et al. Factors contributing to the racial differences in prostate cancer mortality. BJU Int. 2005; 96(9):1247-52. [PubMed: 16287439] 


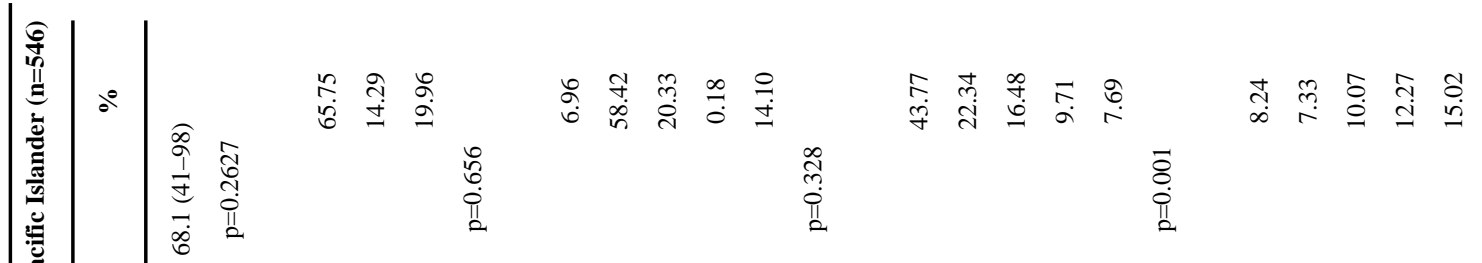

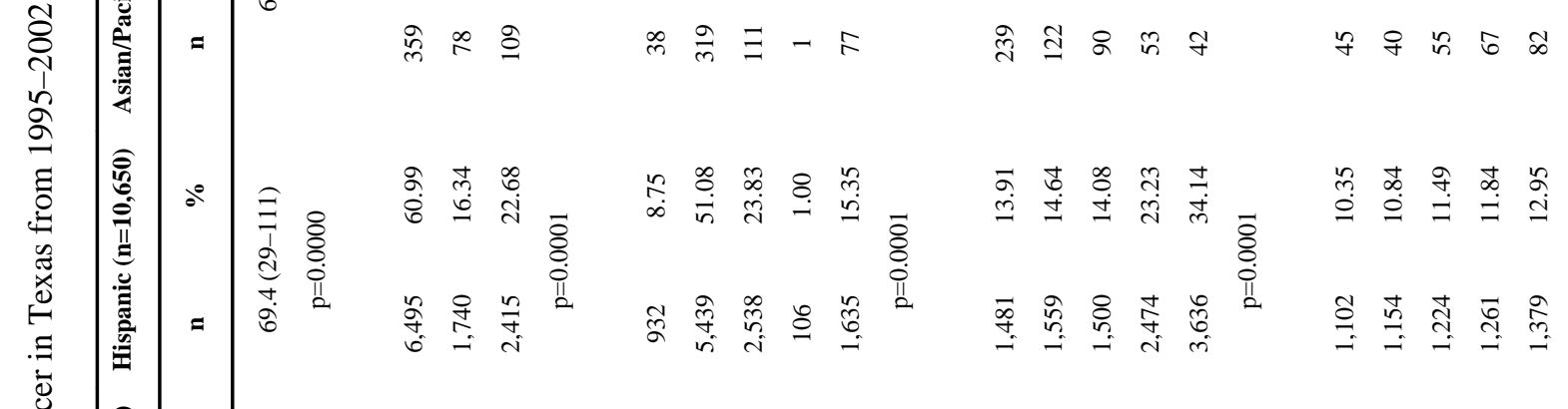

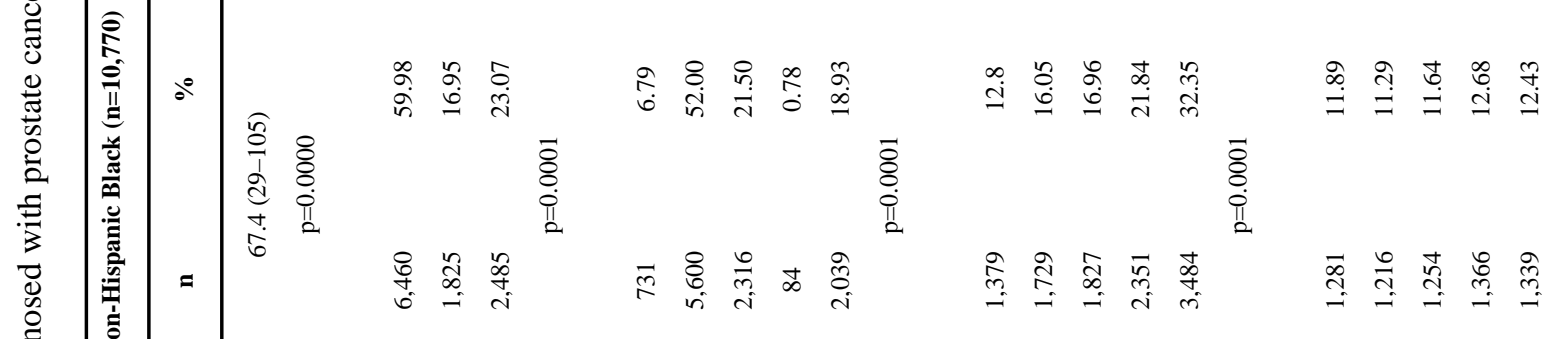

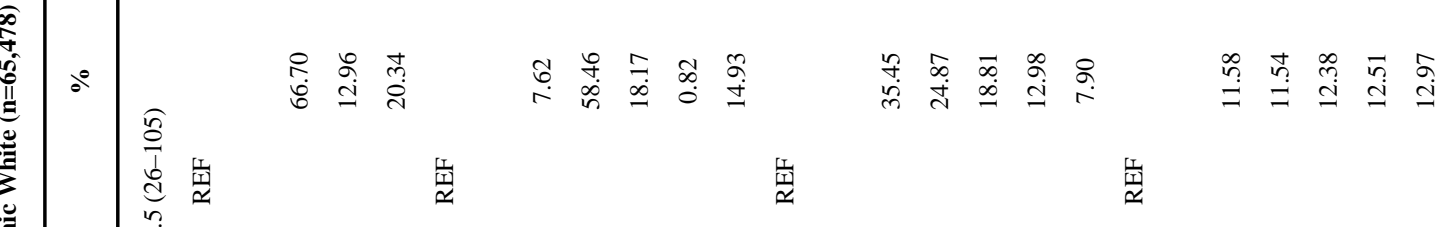




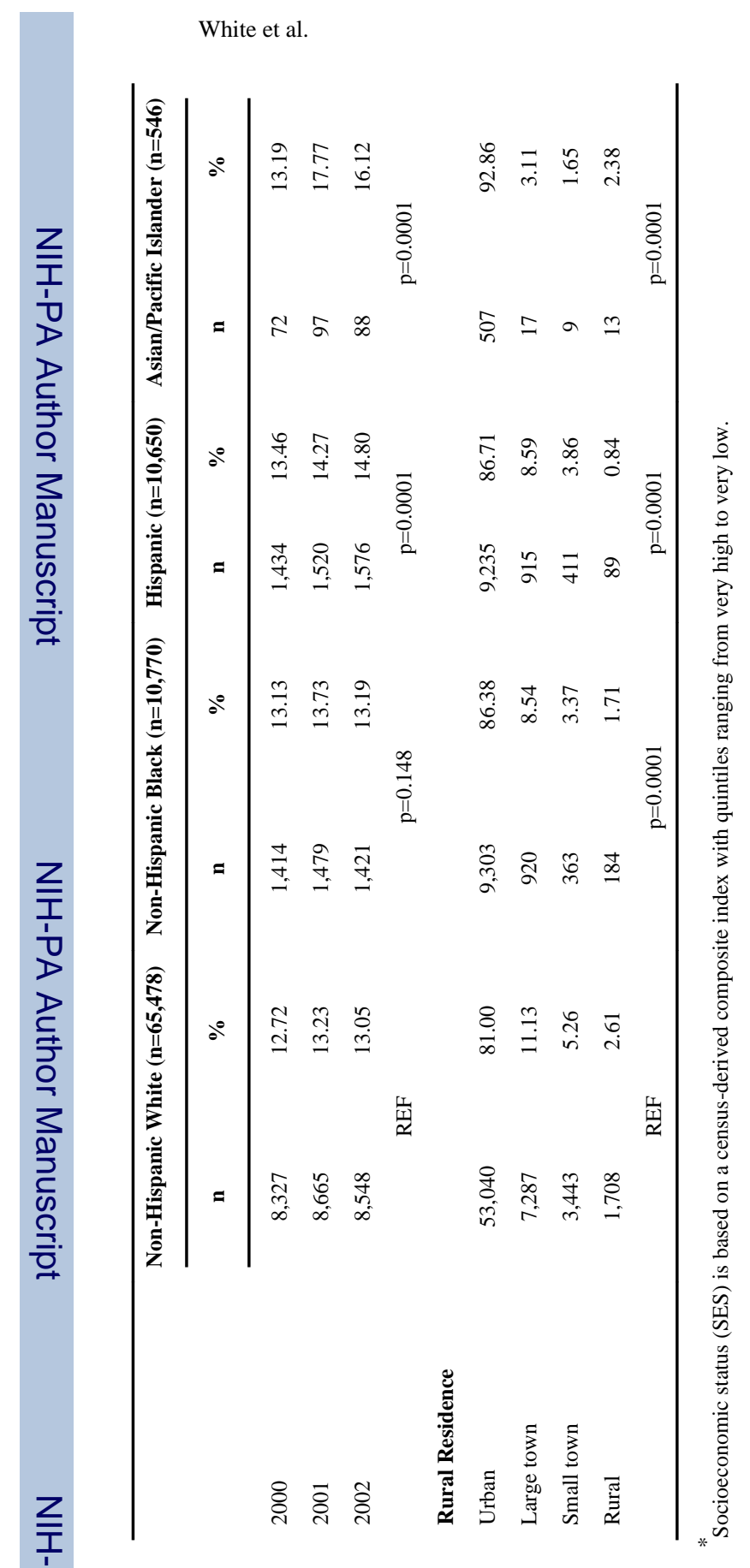

Page 11 


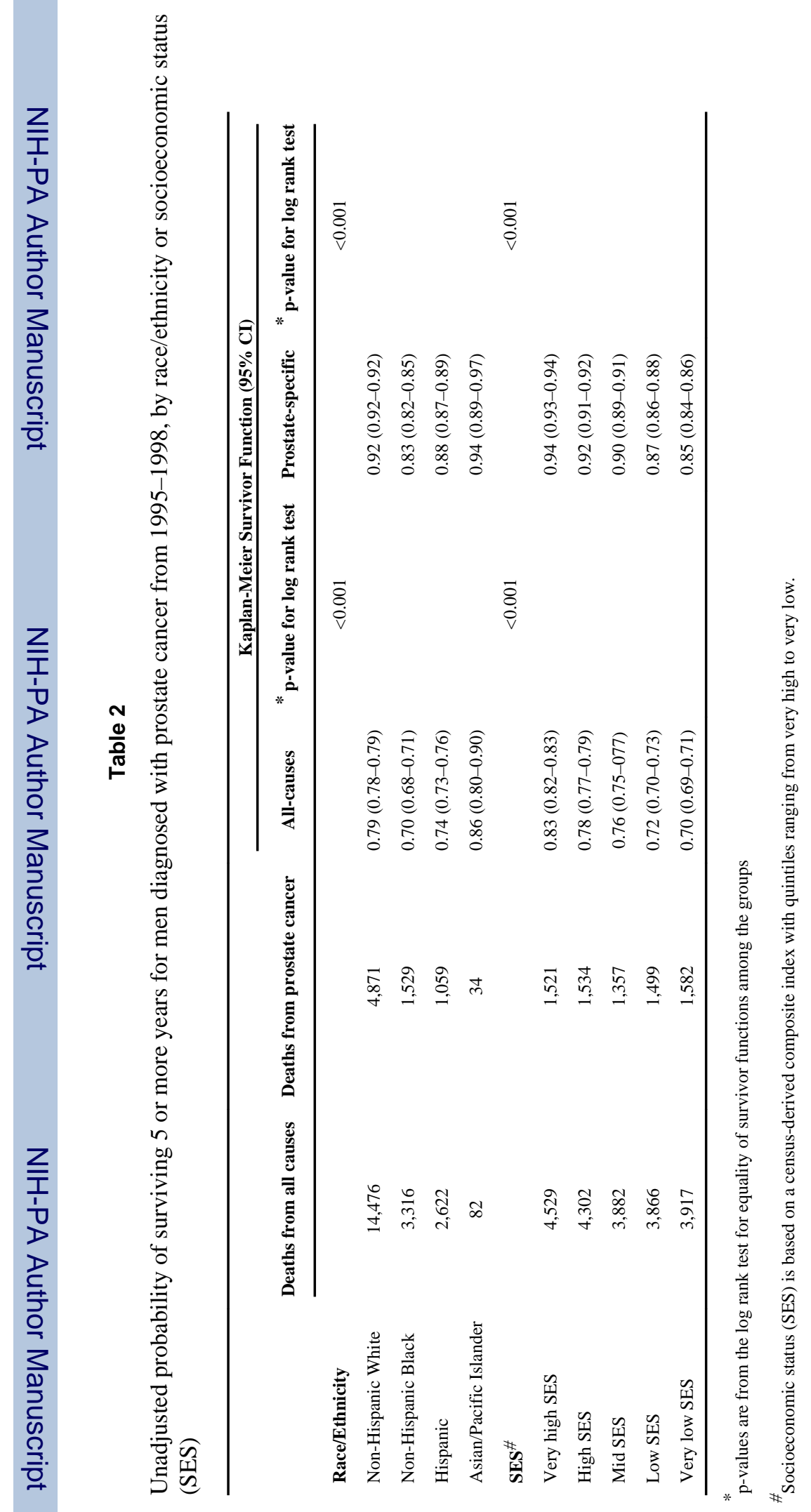


Table 3

Mortality associated with race/ethnicity in men with prostate carcinoma by SEER Summary stage at diagnosis, 1995-2002

\begin{tabular}{|c|c|c|c|c|}
\hline & \multicolumn{4}{|c|}{ Adjusted Hazard Ratio (95\% CI) for Mortality } \\
\hline & ** Overall & * Localized Stage & * Regional/Distant Stage & * Unknown Stage \\
\hline \multicolumn{5}{|l|}{ Race/ethnicity } \\
\hline Non-Hispanic White & $1.00 \mathrm{REF}$ & $1.00 \mathrm{REF}$ & $1.00 \mathrm{REF}$ & $1.00 \mathrm{REF}$ \\
\hline Non-Hispanic Black & $1.36(1.30-1.42)$ & $1.28(1.19-1.36)$ & $1.49(1.37-1.63)$ & $1.35(1.25-1.46)$ \\
\hline Hispanic & $0.96(.92-1.00)$ & $0.93(0.87-1.00)$ & $1.02(0.93-1.12)$ & $0.95(0.88-1.03)$ \\
\hline Asian/Pacific Islander & $0.65(0.52-0.82)$ & $0.49(0.33-0.73)$ & $0.76(0.51-1.14)$ & $0.83(0.56-1.24)$ \\
\hline \multicolumn{5}{|l|}{ SES } \\
\hline Very high SES & 1.00 REF & $1.00 \mathrm{REF}$ & $1.00 \mathrm{REF}$ & $1.00 \mathrm{REF}$ \\
\hline High SES & $1.16(1.11-1.21)$ & $1.14(1.07-1.22)$ & $1.26(1.14-1.39)$ & $1.11(1.02-1.20)$ \\
\hline Mid SES & $1.22(1.17-1.28)$ & $1.28(1.20-1.37)$ & $1.19(1.07-1.32)$ & $1.16(1.06-1.26)$ \\
\hline Low SES & $1.35(1.28-1.41)$ & $1.41(1.31-1.51)$ & $1.33(1.20-1.48)$ & $1.24(1.13-1.35)$ \\
\hline Very low SES & $1.34(1.28-1.41)$ & $1.43(1.33-1.54)$ & $1.34(1.20-1.49)$ & $1.18(1.08-1.30)$ \\
\hline Age & $1.083(1.081-1.085)$ & $1.095(1.092-1.098)$ & $1.067(1.063-1.071$ & $1.072(1.069-1.076)$ \\
\hline \multicolumn{5}{|l|}{ Tumor Grade } \\
\hline Well differentiated & $1.00 \mathrm{REF}$ & $1.00 \mathrm{REF}$ & $1.00 \mathrm{REF}$ & 1.00 REF \\
\hline Moderately differentiated & $0.94(.89-1.00)$ & $0.98(0.92-1.05)$ & $0.98(0.78-1.22)$ & $1.00(0.88-1.13)$ \\
\hline Poorly differentiated & $1.44(1.35-1.53)$ & $1.33(1.23-1.44)$ & $1.86(1.49-2.32)$ & $1.79(1.58-2.04)$ \\
\hline Undifferentiated & $2.10(1.86-2.39)$ & $1.75(1.40-2.19)$ & $2.82(2.16-3.69)$ & $2.87(2.24-3.68)$ \\
\hline Unknown/Missing & $1.65(1.55-1.76)$ & $1.15(1.04-1.26)$ & $3.20(2.56-4.01)$ & $1.83(1.62-2.06)$ \\
\hline \multicolumn{5}{|l|}{ Rural Residence } \\
\hline Urban & $1.00 \mathrm{REF}$ & 1.00 REF & $1.00 \mathrm{REF}$ & 1.00 REF \\
\hline Large Town & $1.02(0.97-1.06)$ & $1.02(0.95-1.09)$ & $1.07(0.97-1.18)$ & $1.00(0.92-1.08)$ \\
\hline Small Town & $1.06(0.99-1.13)$ & $1.03(0.94-1.14)$ & $1.06(0.92-1.21)$ & $1.09(0.98-1.20)$ \\
\hline Rural & $0.99(0.92-1.10)$ & $0.94(0.81-1.09)$ & $0.98(0.80-1.21)$ & $1.05(0.90-1.23)$ \\
\hline \multicolumn{5}{|c|}{ Adjusted for stage and year of diagnosis } \\
\hline
\end{tabular}


Table 4

Prostate cancer-specific mortality associated with race/ethnicity in men with prostate carcinoma by SEER Summary stage at diagnosis, 1995-2002

\begin{tabular}{|c|c|c|c|c|}
\hline & \multicolumn{4}{|c|}{ Adjusted Hazard Ratio ( $95 \%$ CI) for Mortality } \\
\hline & ** Overall & * Localized Stage & ${ }^{*}$ Regional/Distant Stage & ${ }^{*}$ Unknown Stage \\
\hline \multicolumn{5}{|l|}{ Race/ethnicity } \\
\hline Non-Hispanic White & $1.00 \mathrm{REF}$ & $1.00 \mathrm{REF}$ & $1.00 \mathrm{REF}$ & $1.00 \mathrm{REF}$ \\
\hline Non-Hispanic Black & $1.70(1.58-1.83)$ & $1.52(1.30-1.78)$ & $1.70(1.52-1.89)$ & $1.80(1.57-2.05)$ \\
\hline Hispanic & $1.11(1.02-1.20)$ & $1.23(1.05-1.44)$ & $1.07(.95-1.20)$ & $1.07(.93-1.24)$ \\
\hline Asian/Pacific Islander & $0.68(.46-1.00)$ & $0.42(.13-1.30)$ & $0.76(.46-1.24)$ & $0.74(.35-1.56)$ \\
\hline \multicolumn{5}{|l|}{ SES $^{\#}$} \\
\hline Very high SES & $1.00 \mathrm{REF}$ & $1.00 \mathrm{REF}$ & $1.00 \mathrm{REF}$ & $1.00 \mathrm{REF}$ \\
\hline High SES & $1.21(1.12-1.32)$ & $1.27(1.07-1.51)$ & $1.28(1.13-1.45)$ & $1.04(.89-1.22)$ \\
\hline Mid SES & $1.20(1.10-1.31)$ & $1.34(1.12-1.60)$ & $1.17(1.02-1.33)$ & $1.14(.97-1.33)$ \\
\hline Low SES & $1.44(1.32-1.57)$ & $1.90(1.59-2.26)$ & $1.26(1.10-1.44)$ & $1.31(1.12-1.53)$ \\
\hline Very low SES & $1.36(1.25-1.49)$ & $1.70(1.41-2.04)$ & $1.34(1.17-1.53)$ & $1.14(0.97-1.34)$ \\
\hline Age & $1.075(1.072-1.079$ & $1.107(1.099-1.114)$ & $1.065(1.061-1.069$ & $1.065(1.059-1.071$ \\
\hline \multicolumn{5}{|l|}{ Tumor Grade } \\
\hline Well differentiated & $1.00 \mathrm{REF}$ & 1.00 REF & 1.00 REF & 1.00 REF \\
\hline Moderately differentiated & $1.77(1.44-2.16)$ & $2.33(1.72-3.16)$ & $1.42(.94-2.14)$ & $1.49(1.03-2.15)$ \\
\hline Poorly differentiated & $5.83(4.77-7.12)$ & $8.22(6.08-11.12)$ & $3.98(2.65-5.96)$ & $7.00(4.88-10.03)$ \\
\hline Undifferentiated & $10.84(8.54-13.77)$ & $19.66(13.08-29.55)$ & $7.13(4.60-11.04)$ & $13.45(8.45-21.48)$ \\
\hline Unknown/Missing & $6.85(5.60-8.38)$ & $4.59(3.29-6.39)$ & $7.24(4.82-10.89)$ & $6.38(4.48-9.09)$ \\
\hline \multicolumn{5}{|l|}{ Rural Residence } \\
\hline Urban & $1.00 \mathrm{REF}$ & $1.00 \mathrm{REF}$ & $1.00 \mathrm{REF}$ & 1.00 REF \\
\hline Large Town & $1.04(.96-1.13)$ & $1.15(.97-1.36)$ & $1.11(.98-1.26)$ & $0.90(.781-1.05)$ \\
\hline Small Town & $1.11(.99-1.24)$ & $1.14(.90-1.45)$ & $1.11(.94-1.32)$ & $1.07(.88-1.30$ \\
\hline Rural & $0.95(.79-1.14)$ & $0.74(.49-1.14)$ & $0.93(.712-1.22)$ & $1.04(0.78-1.40)$ \\
\hline \multicolumn{5}{|c|}{ * Also adjusted for stage and year of diagnosis } \\
\hline
\end{tabular}


Table 5

Analysis of predictors of prostate cancer specific mortality for men diagnosed with prostate carcinoma, 19952002

\begin{tabular}{lccc}
\hline & $\begin{array}{c}\text { Model 1 } \\
\text { Hazard Ratio (95\% CI) }\end{array}$ & $\begin{array}{c}\text { *Model 2 } \\
\text { Hazard Ratio (95\% CI) }\end{array}$ & $\begin{array}{c}\text { *Model 3 } \\
\text { Hazard Ratio (95\% CI) }\end{array}$ \\
\hline Race/ethnicity & & & \\
Non-Hispanic White & $1.00 \mathrm{REF}$ & $1.00 \mathrm{REF}$ & $1.00 \mathrm{REF}$ \\
Non-Hispanic Black & $2.01(1.89-2.17)$ & $1.84(1.71-1.97)$ & $1.70(1.58-1.83)$ \\
Hispanic & $1.55(1.43-1.67)$ & $1.20(1.11-1.29)$ & $1.11(1.02-1.20)$ \\
Asian/Pacific Islander & $0.88(0.60-1.30)$ & $0.79(.54-1.16)$ & $0.68(.46-1.00)$ \\
\hline
\end{tabular}

Model 1 is unadjusted.

Model 2 adjusted for age (continuous), year of diagnosis, tumor stage and tumor grade, in addition to factors in Model 1.

Model 3 adjusted for socioeconomic status (based on census-derived composite index, in quintiles), rural residence, in addition to factors in Model 2 . 